\title{
Regulation of inflammation by selenium and selenoproteins: impact on eicosanoid biosynthesis
}

\author{
S. A. Mattmiller ${ }^{1}$, Bradley A. Carlson ${ }^{2}$ and L. M. Sordillo ${ }^{1} *$ \\ ${ }^{1}$ College of Veterinary Medicine, Michigan State University, East Lansing, MI 48824, USA \\ ${ }^{2}$ Section on the Molecular Biology of Selenium, Laboratory of Cancer Prevention, National Cancer Institute, National Institutes of Health, Bethesda, \\ MD 20892, USA
}

(Received 25 November 2012 - Final revision received 29 April 2013 - Accepted 1 May 2013)

Journal of Nutritional Science (2013), vol. 2, e28, page 1 of 13

doi:10.1017/jns.2013.17

Abstract

Uncontrolled inflammation is a contributing factor to many leading causes of human morbidity and mortality including atherosclerosis, cancer and diabetes. Se is an essential nutrient in the mammalian diet that has some anti-inflammatory properties and, at sufficient amounts in the diet, has been shown to be protective in various inflammatory-based disease models. More recently, Se has been shown to alter the expression of eicosanoids that orchestrate the initiation, magnitude and resolution of inflammation. Many of the health benefits of Se are thought to be due to antioxidant and redox-regulating properties of certain selenoproteins. The present review will discuss the existing evidence that supports the concept that optimal Se intake can mitigate dysfunctional inflammatory responses, in part, through the regulation of eicosanoid metabolism. The ability of selenoproteins to alter the biosynthesis of eicosanoids by reducing oxidative stress and/or by modifying redox-regulated signalling pathways also will be discussed. Based on the current literature, however, it is clear that more research is necessary to uncover the specific beneficial mechanisms behind the anti-inflammatory properties of selenoproteins and other Se metabolites, especially as related to eicosanoid biosynthesis. A better understanding of the mechanisms involved in Se-mediated regulation of host inflammatory responses may lead to the development of dietary intervention strategies that take optimal advantage of its biological potency.

Key words: Selenium: Selenoproteins: Eicosanoid biosynthesis: Inflammation

Uncontrolled inflammatory responses can contribute to the pathogenesis of many health disorders. Dysfunctional or uncontrolled inflammation can be characterised as a chronic low-grade inflammation such as that observed in diabetes, obesity and atherosclerosis ${ }^{(1,2)}$. Alternatively, uncontrolled inflammation also may manifest as an exacerbated acute inflammation as observed in diseases such as sepsis and mastitis ${ }^{(3)}$. Eicosanoids are a class of lipid mediators that constitute one of the several pathways that regulate the inflammatory response and are biosynthesised by many cell types including endothelial cells and leucocytes. During uncontrolled inflammation, a combination of the overproduction of proinflammatory eicosanoids and a diminished synthesis of anti-inflammatory eicosanoids can contribute to an improper and incomplete resolution process. Current non-steroidal antiinflammatory drug therapies that target specific enzymes involved in eicosanoid biosynthesis have limited efficacy in controlling some inflammatory-based diseases and can cause adverse side effects in both humans and veterinary species ${ }^{(4)}$. Therefore, there is a growing interest to identify alternative

\footnotetext{
Abbreviations: $15 \mathrm{~d}-\mathrm{PGJ}_{2}, 15$-deoxy- ${ }^{12,14} \mathrm{PGJ}_{2}$; 15-HETE, 15(S)-hydroxy-(5Z,8Z,11Z,13E)-eicosatetraenoic acid; 15-HPETE, 15-hydroperoxyeicosatetraenoic acid; AA, arachidonic acid; ASK-1, apoptosis signal-regulating kinase 1; COX, cyclo-oxygenase; FAHP, fatty acid hydroperoxide; GPx, glutathione peroxidase; GPx4, glutathione peroxidase-4; HO-1, haeme oxygenase-1; HPETE, hydroperoxyeicosatetraenoic acid; H-PGDS, haematopoietic PGD 2 synthase; HPODE, hydroperoxyoctadecadienoic acid; LA, linoleic acid; LOX, lipoxygenase; LPS, lipopolysaccharide; LT, leukotriene; $\mathrm{LTA}_{4} \mathrm{H}$, leukotriene $\mathrm{A}_{4}$ hydrolase; MAPK, mitogen-activated protein kinase; ppm, parts per million; ROS, reactive oxygen species; Sepp1, selenoprotein P plasma 1; Trx, thioredoxin; TrxR, thioredoxin reductase; TX, thromboxane; TXB 2 , thromboxane $\mathrm{B}_{2}$.
}

* Corresponding author: Dr Lorraine M. Sordillo, fax +1517432 8823, email Sordillo@msu.edu 
therapeutic strategies to regulate uncontrolled inflammation through dietary intervention. The potential of optimising host inflammatory responses by modifying Se dietary intake has been explored in several inflammatory-based disease models such as cancer ${ }^{(5)}, \mathrm{CVD}^{(6)}$, mastitis ${ }^{(7)}$ and osteoporo$\operatorname{sis}^{(8)}$. Although Se nutritional status was often associated with the magnitude and duration of inflammation, the underlying beneficial mechanisms ascribed to this micronutrient are not fully described. The aim of the present review is to assess how the antioxidant and redox-regulating properties of certain selenoproteins can contribute to the beneficial properties of Se nutrition in controlling inflammatory-based diseases. The ability of selenoproteins to regulate eicosanoid biosynthetic pathways in both whole-animal models of disease and in individual cell types will be critically evaluated as potential antiinflammatory mechanisms resulting from optimal Se intake. A greater understanding of the factors that can regulate the delicate balance between the initiation and resolution of inflammatory responses is needed in order to help diminish the morbidity and mortality associated with the pathology of inflammatory-based diseases.

\section{Selenium: an essential micronutrient with anti-inflammatory} properties

\section{Selenium and inflammatory diseases}

Se was once considered a toxin when livestock and poultry suffered from alkali disease after consuming grass containing 10-20 parts per million (ppm) Se. Subsequent studies confirmed the potential for Se poisoning when laboratory rodents supplemented with 5-15 ppm of dietary Se displayed varying degrees of pathology ${ }^{(9)}$. In contrast, others found that Se deficiency (diets containing less than $0 \cdot 1 \mathrm{ppm}$ Se) caused diseases such as white muscle disease in cattle and lambs ${ }^{(10)}$ and Keshan disease in human subjects ${ }^{(11)}$. Based on these earlier studies, Se is now understood to be an essential micronutrient in the mammalian diet and our knowledge of its metabolism (Fig. 1) and beneficial functions has grown immensely. Current recommendations indicate that the upper tolerable intake of Se is between 90 and $400 \mu \mathrm{g} / \mathrm{d}$ (recommended daily intake between 30 and $55 \mu \mathrm{g} / \mathrm{d}$ ) for humans $^{(12)}$ and $0.4 \mathrm{mg} / \mathrm{kg}$ body weight in rodents ${ }^{(13)}$. In a review and meta-analysis of the literature, Huang et al. ${ }^{(14)}$ found that supplementation with Se (between 500 and 2000 $\mu \mathrm{g} / \mathrm{d}$ for various durations) in critically ill patients decreased mortality rates associated with sepsis. Additionally, women with normal pregnancies exhibited significantly higher blood Se concentrations compared with women with pre-eclampsia, the leading cause of perinatal and maternal mortality globally ${ }^{(15)}$. In a model of inflammatory bowel disease, rats fed a high-Se diet ( $2 \mu \mathrm{g} / \mathrm{g}$ body weight) for $21 \mathrm{~d}$ exhibited decreased colonic tissue necrosis ${ }^{(16)}$. It is important to note, however, that not all clinical trials involving Se supplementation improved health outcomes in a significant way. Recently published results from The Selenium and Vitamin E Cancer Prevention Trial (SELECT) showed that Se supplementation $(200 \mu \mathrm{g} / \mathrm{d})$, alone or with vitamin $\mathrm{E}$ for a period between 7 and 12 years, did not prevent diseases such as prostate, lung or colon cancers and there were no significant differences in cardiovascular events or diabetes between treatment groups in men ${ }^{(17)}$. Based on these equivocal findings, it is now clear that more research is required to better understand the underlying mechanisms of Se's beneficial health properties in order to design nutritional intervention strategies that yield more consistent and positive results across a range of human health disorders.

Selenium functions as an antioxidant through the activity of selenoproteins

Although the importance of Se to health is not fully understood, one well-characterised function of Se is its ability to mitigate oxidative stress through antioxidant-functioning selenoproteins (Table 1), including the well-studied glutathione peroxidase (GPx) and thioredoxin reductase (TrxR) families ${ }^{(18,19)}$. Oxidative stress occurs when the production of free radicals, including reactive oxygen species (ROS), reactive nitrogen species (RNS), oxidised proteins and oxidised lipids, outweighs an organism's antioxidant capabilities resulting in cellular/tissue damage ${ }^{(20)}$. The GPx and TrxR selenoproteins contain a selenocysteine in their active site making them suitable for oxidation/reduction reactions (Fig. 2). Whereas GPx1 can reduce ROS in the cytoplasm, glutathione peroxidase-4 (GPx4) has the ability to reduce fatty acid hydroperoxides (FAHP) and phospholipid hydroperoxides within cellular membranes (Fig. 2(a)) ${ }^{(21,22)}$. A longer, alternative transcript of GPx4 also was localised to mitochondrial membranes ${ }^{(23)}$ and shown to maintain ATP production during oxidative stress which could have implications on cellular activity and function during disease ${ }^{(24)}$. Thioredoxin (Trx) reduces a variety of radicals including lipid hydroperoxides, protein thiols and ROS/RNS. Oxidised Trx is then restored to its reduced form by TrxR selenoproteins (Fig. 2(b)). Selenoproteins W, K and P (Sepw1, Selk, Sepp1) also have been suggested to have antioxidant capabilities, but mechanisms are less understood ${ }^{(25,26)}$.

Oxidative stress is a contributing factor in inflammatory disease pathologies including atherosclerosis ${ }^{(27)}$, diabetes ${ }^{(28)}$ and mastitis ${ }^{(29)}$ among others. There is ample evidence to indicate that selenoproteins can interrupt disease pathogenesis through antioxidant-dependent mechanisms. Numerous studies in human subjects, food-animal species and rodent models demonstrated a negative correlation between measures of selenoprotein activity and disease severity due to oxidative stress ${ }^{(30-32)}$. Direct evidence of the importance of selenoproteins in mitigating oxidative stress was demonstrated in transgenic studies where overexpression of GPx4 significantly reduced lipid peroxidation in atherosclerosis and ischaemiareperfusion mouse models ${ }^{(33,34)}$. Several in vitro studies also demonstrated that TrxR1 and selenoprotein P could directly reduce the lipid hydroperoxide, 15-hydroperoxyeicosatetraenoic acid (15-HPETE), to its corresponding hydroxyl (15(S)-hydroxy(5Z,8Z,11Z,13E)-eicosatetraenoic acid; 15-HETE) ${ }^{(35-37)}$, thus having implications in reducing atherosclerotic lesion formation as a consequence of oxidative stress ${ }^{(38)}$. Collectively, these studies 


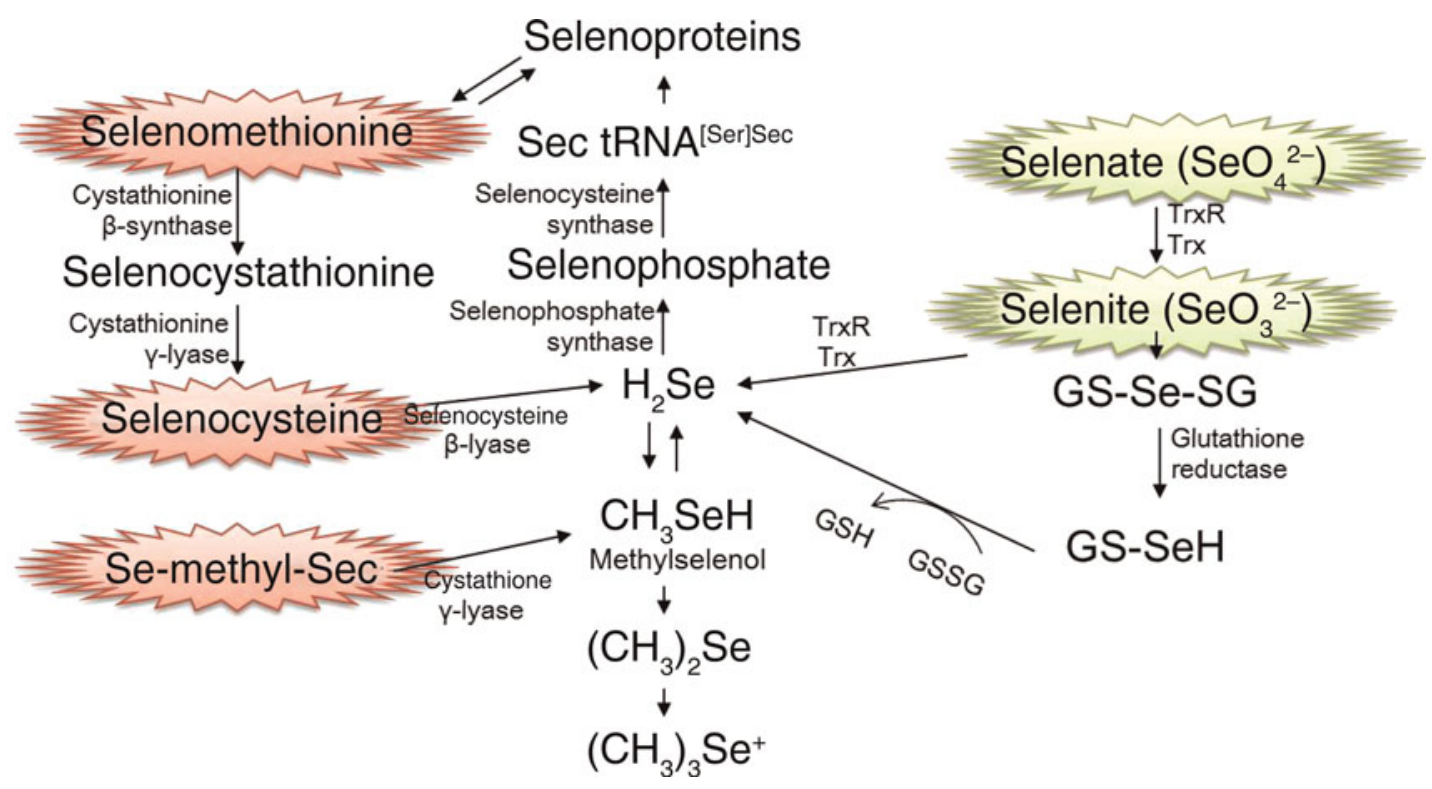

Fig. 1. Selenium metabolism from different dietary sources. Dietary intake sources of selenium include the inorganic selenate and selenite (depicted in the green stars), whereas organic sources (depicted in the red stars) are obtained from animal and plant sources that provide selenium in the form of selenocysteine (Sec), selenomethionine and selenium-methylselenocysteine (Se-methyl-Sec). Inorganic forms of selenium are reduced by thioredoxin reductase (TrxR) and thioredoxin (Trx) or converted to selenodiglutathione (GS-Se-SG) by glutathione disulfide (GSSG), reduced by glutathione reductase to glutathioselenol (GS-SeH), then converted to hydrogen selenide $\left(\mathrm{H}_{2} \mathrm{Se}\right)$ in a reaction with GSSG. Selenoproteins are broken down by lyases to form $\mathrm{H}_{2} \mathrm{Se}$ in intestinal enterocytes. $\mathrm{H}_{2} \mathrm{Se}$ can then be converted into selenophosphate by selenophosphate synthase and $\mathrm{Sec}$ by selenocysteine synthase for incorporation of $\mathrm{Sec}$ into selenoproteins. $\mathrm{H}_{2} \mathrm{Se}$ can also be converted into methylated metabolites by methyltransferases which are primarily excreted through exhalation, urine and faeces. GSH, glutathione.

support the contention that optimally functioning antioxidant selenoproteins may be crucial for reducing excess free radical accumulation and preventing oxidative tissue damage during acute or chronic inflammation.

\section{Role of selenoproteins in cellular redox signalling}

Another way in which selenoproteins may protect against immunopathology associated with uncontrolled inflammatory

Table 1. Summary of mammalian selenoproteins with characterised functions*

\begin{tabular}{|c|c|}
\hline Selenoprotein & Proposed function \\
\hline GPx: 1, 2, 3, 4, 6† & Antioxidant/modify redox tone \\
\hline TrxR: 1, 2, 3 & $\begin{array}{l}\text { Implicated in regulation of inflammatory } \\
\text { signalling }\end{array}$ \\
\hline Sepw1, Selk, Sepp1 & Antioxidant/reduce FAHP \\
\hline SelR & Reduction of methyl sulfoxy groups \\
\hline Sepp1 & Se transport in blood/reduce FAHP \\
\hline Sephs2 & Selenoprotein synthesis \\
\hline $\begin{array}{l}\text { Sep15, Selm, Seln, } \\
\text { Sels }\end{array}$ & $\begin{array}{l}\text { Involved in misfolded protein response } \\
\text { in the ER }\end{array}$ \\
\hline SelH & Redox-sensitive DNA-binding protein \\
\hline Sell & Phospholipid synthesis \\
\hline Sepn1 & Ca signalling in the ER \\
\hline DIO 1, 2, 3 & Thyroid hormone synthesis \\
\hline SelO, SelV & Unknown function \\
\hline
\end{tabular}

GPx, glutathione peroxidase; TrxR, thioredoxin reductase; Sepw1, selenoprotein W1; Selk, selenoprotein K; Sepp1, selenoprotein P plasma 1; FAHP, fatty acid hydroperoxide; SelR, selenoprotein R; Sephs2, selenoprotein HS2; Sep15, selenoprotein 15; Selm; selenoprotein M; Seln, selenoprotein N; Sels, selenoprotein S; ER, endoplasmic reticulum; SelH, selenoprotein $\mathrm{H}$; Sell, selenoprotein I; Sepn1, selenoprotein N1; DIO, deiodinase; SelO, selenoprotein O; SelV, selenoprotein V.

${ }^{*}$ Adapted from Lu \& Holmgren ${ }^{(31)}$, Heras et al. ${ }^{(104)}$ and Kryukov et al. ${ }^{(105)}$

†GPx6 contains a selenocysteine (Sec) in man and a cysteine (Cys) in rodents. responses is through redox regulation of inflammatory signalling. The redox state of cells or tissues can be defined as the ratio of oxidised and reduced forms of specific redox couples $^{(39)}$. Some redox couples relevant to inflammation include $\mathrm{NADP}^{+}$:NADPH, glutathione disulfide: 2 glutathiones $(\mathrm{GSH})$, and oxidised thioredoxin $(\operatorname{Trx}(\mathrm{SS}))$ :reduced thioredoxin $\left(\operatorname{Trx}(\mathrm{SH})_{2}\right)$. Thioredoxin and glutathione redox couples function with the help of TrxR and GPx selenoproteins, respectively. Into et $a l^{(40)}$ found that GSH was capable of modifying nitrosylated forms of the myeloid differentiation factor 88 (MyD88) adaptor protein which enhanced signalling through the toll-like receptor (TLR4) pathway during acute inflammation and resulted in altered IL-8 and IL-6 expression $^{(40)}$. Mitogen-activated protein kinase (MAPK) signalling also can be affected by redox tone. Apoptosis signalregulating kinase 1 (ASK-1) is a MAPK intermediate that activates downstream pro-inflammatory and pro-apoptotic signalling cascades ${ }^{(41,42)}$. Mammalian Trx is a direct inhibitor of ASK-1 kinase activity and a negative regulator of ASK-1-dependent gene expression ${ }^{(41)}$. The interaction between ASK-1 and Trx was found to be highly dependent on redox status since oxidation of Trx by ROS results in ASK-1 activation. In contrast, the reduced Trx blocked ASK-1 dependent signalling, indicating a protective role of selenoproteins in regulation of apoptosis during oxidative stress $^{(43)}$.

Known as the central regulator of inflammatory gene expression, NF- $\mathrm{\kappa B}$ similarly can be redox regulated at several levels. Vunta et al. ${ }^{(44,45)}$ reported an association between increased pro-inflammatory $\mathrm{NF}-\kappa \mathrm{B}$ activation, increased TNF $\alpha$ production and decreased GPx1 activity when macrophages were cultured in Se-deficient media that contained only 
(a)

$\mathrm{R}-\mathrm{OOH}+2 \mathrm{GSH} \stackrel{\mathrm{GPx}}{\longrightarrow} \mathrm{R}-\mathrm{OH}+\mathrm{H}_{2} \mathrm{O}+\mathrm{GSSG}$

GSSG $+\mathrm{H}^{+}+\mathrm{NADPH} \stackrel{\text { Glutathione reductase }}{\longrightarrow} 2 \mathrm{GSH}+\mathrm{NADP}^{+}$

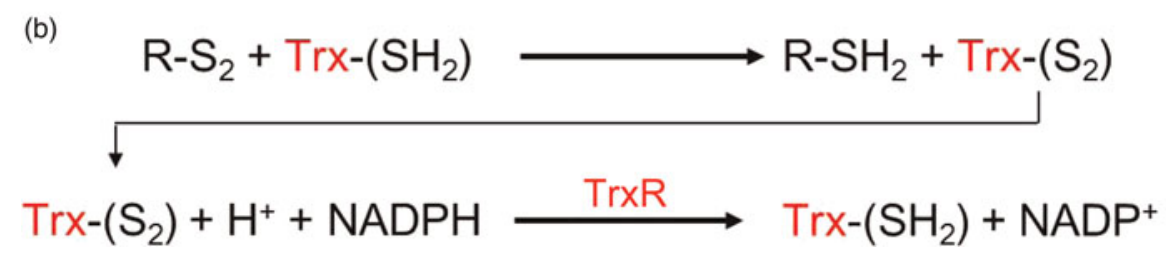

Fig. 2. General reaction mechanisms for antioxidant glutathione peroxidase (GPx) and thioredoxin reductase (TrxR). (a) GPx catalyses the chemical reduction of lipid peroxides or $\mathrm{H}_{2} \mathrm{O}_{2}$ to respective alcohols and water by glutathione (GSH) which forms glutathione disulfide (GSSG). Glutathione reductase catalyses the reduction of GSSG back to GSH in the presence of NADPH. (b) Oxidised protein disulfides and other free radicals are reduced to their corresponding thiols by thioredoxin (Trx). TrxR then catalyses the reduction of oxidised Trx in the presence of NADPH.

$6 \mathrm{pmol} / \mathrm{ml}$ of Se when compared with cells cultures with $2 \mathrm{nmol} / \mathrm{ml}$ of $\mathrm{Se}^{(44,45)}$. Decreased plasma Se $(0 \cdot 37$ (SE 0.05) compared with $0.85(\mathrm{SE} 0 \cdot 09) \mu \mathrm{mol} / \mathrm{l})^{(46)}$ and decreased selenoprotein synthesis ${ }^{(47)}$ in HIV patients were associated with enhanced oxidative stress-induced activation of $\mathrm{NF}-\kappa \mathrm{B}$ which promoted HIV viral transcription. In the cytoplasm, ROS-mediated activation of $\mathrm{NF}-\kappa \mathrm{B}$ can be facilitated through activation of protein kinase $A$ (PKAc) which results in release of NF- $\kappa \mathrm{B}$ from inhibitor of $\kappa \mathrm{B}(\operatorname{IK} \beta)^{(48)}$, and overexpression of Trx caused a decrease in ROS-mediated NF- $\kappa \mathrm{B}$ activity ${ }^{(4)}$. In the nucleus, however, Trx can enhance NF-кB DNA binding by reducing oxidised cysteine resides on $\mathrm{NF}-\kappa \mathrm{B}^{(50)}$. Hirota et al. ${ }^{(51)}$ showed that reduced Trx is primarily found within the cytoplasm of cells; however, upon oxidant stimulation, Trx migrates to the nucleus to enhance NF- $\mathrm{B}-\mathrm{DNA}$ binding. These few examples demonstrate how selenoproteins can both positively and negatively control cell signalling depending on the inflammatory pathway and/or cellular location. Overall, Se nutrition and selenoprotein activity have the potential to improve inflammatory response outcomes in several ways including combating oxidative stress in cells/tissues and through the redox regulation of inflammatory signalling pathways that lead to cytokine/chemokine production. However, another potentially important but less studied mechanism underlying the health benefits of Se may involve the biosynthesis of bioactive lipid mediators that include the eicosanoids (Fig. 3).

\section{Can selemium and selenoproteins have an impact on inflammation through eicosanoid biosynthesis?}

\section{Regulation of inflammation by eicosanoids}

Eicosanoids are a class of lipid mediators that contribute to the orchestration of inflammatory responses. Eicosanoids are synthesised from PUFA substrates primarily found in the cellular membrane including the $n-6$ arachidonic acid (AA) and linoleic acid (LA) or the $n$ - 3 EPA and DHA ${ }^{(52)}$. These fatty acid substrates are oxidised non-enzymically by free radicals or through different enzymic pathways including the cyclo-oxygenases
(COX), lipoxygenases (LOX) and cytochrome P450 pathways to produce both pro-inflammatory and resolving eicosanoids (Fig. 4). Non-enzymic oxidation of AA produces the isoprostane series of PG-like eicosanoids. These lipid mediators have been characterised as biomarkers for oxidative stress ${ }^{(53)}$. As such, they have been quantified in models of inflammatory disease, like atherosclerosis, to identify relationships between disease progression and oxidative damage ${ }^{(54)}$. In addition to the isoprostanes, non-enzymic oxidation of AA or LA can also produce hydroperoxide metabolites HPETE or hydroperoxyoctadecadienoic acid (HPODE), respectively, that are enhanced during oxidative stress ${ }^{(55)}$. Two isoforms of COX enzymes are involved in the enzymic oxidation pathways. Whereas COX-1 is constitutively expressed in cells, COX-2 expression is inducible during inflammation ${ }^{(56,57)}$. COX catalyse the oxidation of $n-6 \mathrm{AA}$ to $\mathrm{PGG}_{2}$ and $\mathrm{PGH}_{2}{ }^{(58)}$. From $\mathrm{PGH}_{2}$, downstream PG synthases produce $\mathrm{PGE}_{2}, \mathrm{PGD}_{2}$, $\mathrm{PGI}_{2}, \mathrm{PGF}_{2 \alpha}$, among others. Alternatively, thromboxane (TX) synthases convert $\mathrm{PGH}_{2}$ to thromboxane $\mathrm{A}_{2}\left(\mathrm{TXA}_{2}\right)$ and thromboxane $\mathrm{B}_{2}\left(\mathrm{TXB}_{2}\right)$. Similar to the COX family, there are several isoforms of LOX involved in the enzymic oxidation of fatty acids. For example, 5-LOX catalyses the oxidation of $n-6$ AA to 5-HPETE which can be further metabolised to produce leukotrienes (LT). Both 15-LOX-1 (12-LOX in mice) and 15-LOX-2 (8-LOX in mice) oxidise AA to $12 / 15-$ HPETE $^{(59)}$. More recent studies have led to the discovery of anti-inflammatory lipoxins (LX) that are produced from the metabolism of 12/15-HPETE intermediates by the 5 -LOX pathway ${ }^{(60)}$. Likewise, $12 / 15-$ LOX-1 can oxidise the n-6 LA into 9-hydroperoxy-10E,12Z-octadecadienoic acid (9-HPODE) and 13S-hydroperoxy-9Z,11E-octadecadienoic acid (13-HPODE) ${ }^{(61)}$. Hydroperoxides can then be reduced to form hydroxyl intermediates (HETE and hydroxy-octadecadienoic acid (HODE)) and further dehydrogenated to form ketone intermediates (oxo-eicosatetraenoic acid (oxoETE) and oxo-octadecadienoic acid (oxoODE)) ${ }^{(62)}$. $n-3$ Fatty acids also can be oxidised by COX and LOX to produce eicosanoids with more anti-inflammatory or resolving properties $^{(52)}$. EPA is metabolised by 5 -LOX and modified 


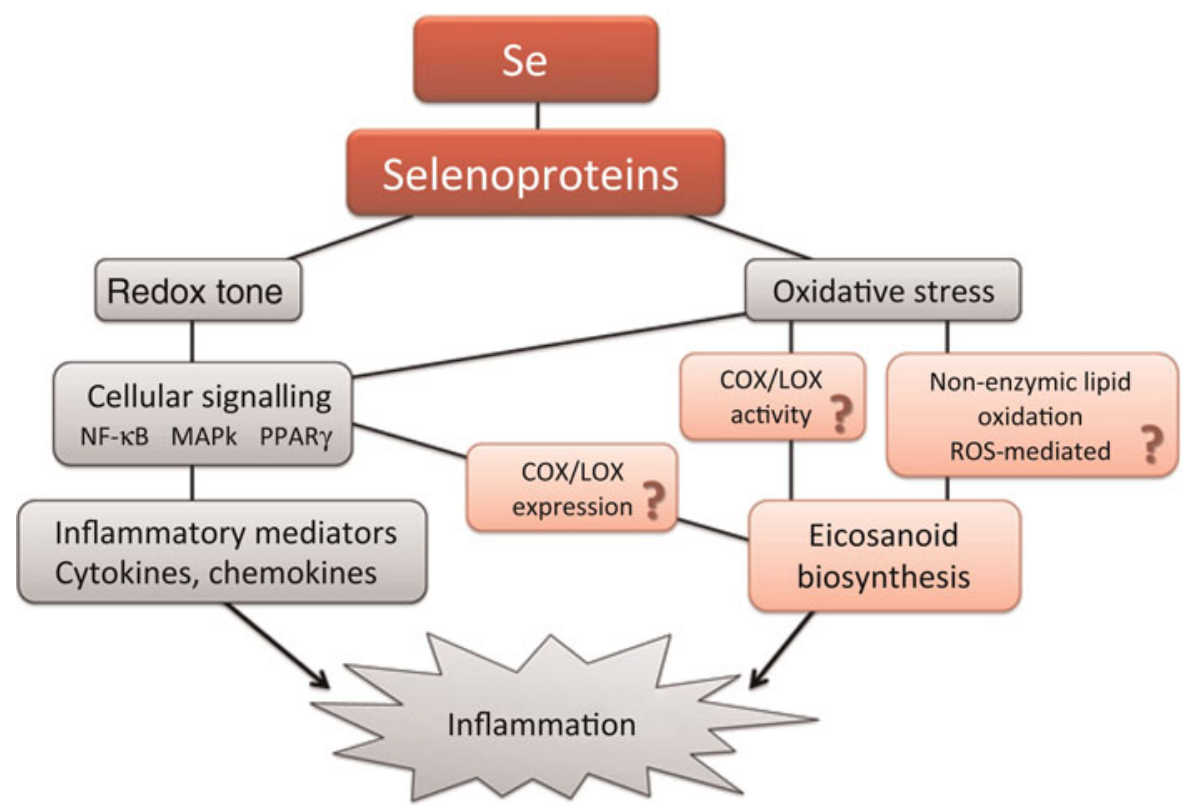

Fig. 3. Selenium's potential impact on the regulation of inflammation. Some of the several ways in which inflammation is mediated through selenoproteins include modifying cellular redox tone which has implications on signalling through the NF-KB, mitogen-activated protein kinase (MAPK) and PPAR $\gamma$ pathways, controlling the expression of inflammatory mediators such as cytokines, chemokines, and cyclo-oxygenase (COX) and lipoxygenase (LOX) enzymes. Selenoproteins also combat oxidative stress which could potentially make an impact on COX/LOX enzyme activity and the production of lipid peroxides oxidised non-enzymically by free radicals. Non-enzymic lipid oxidation, COX/LOX expression and COX/LOX activity have been shown to regulate eicosanoid biosynthesis. Selenium has been studied in the context of each of these regulators and the present review focuses specifically on selenium's impact on eicosanoid biosynthesis. ROS, reactive oxygen species.

Plasma membrane

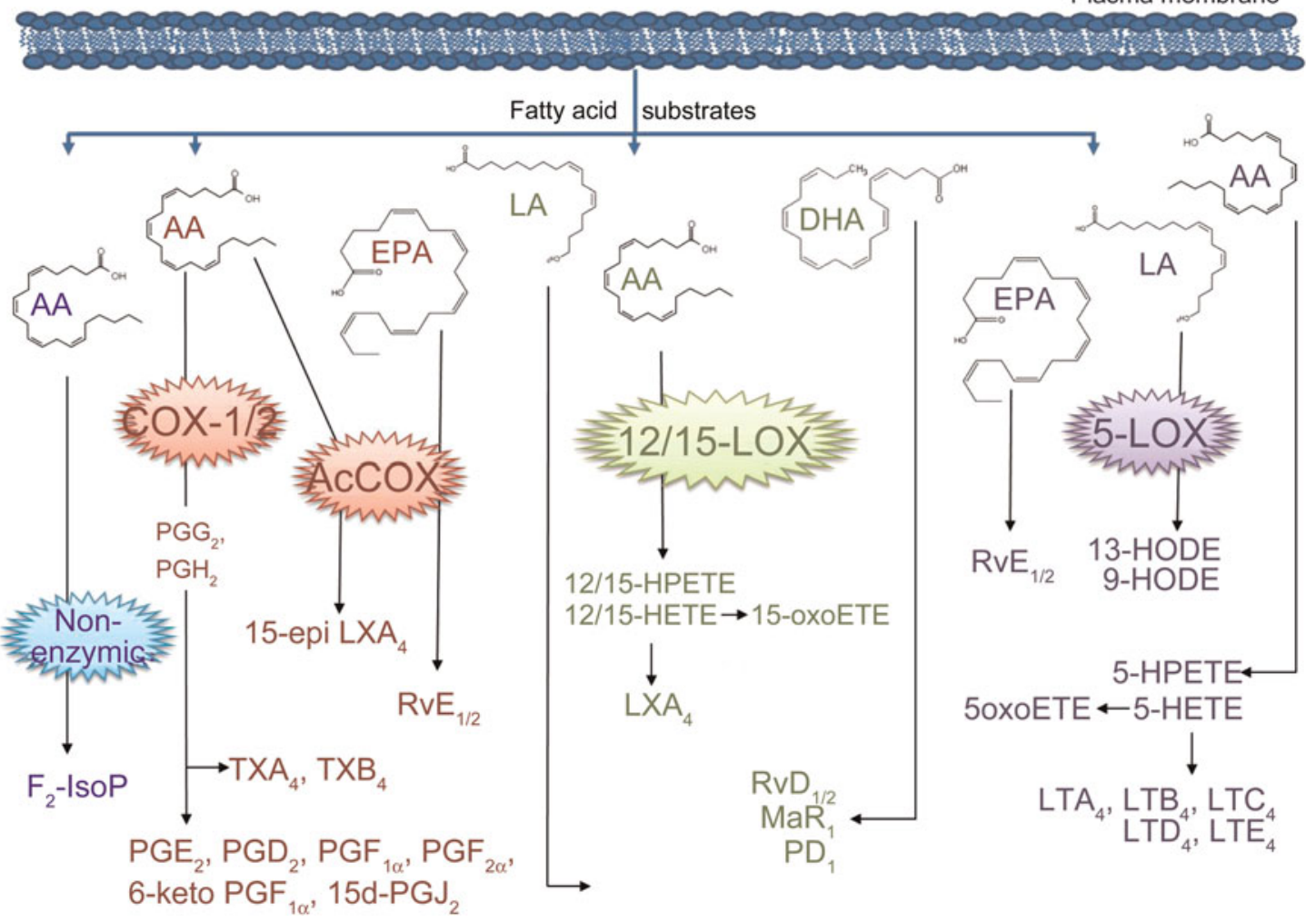

Fig. 4. Eicosanoid biosynthesis pathways. $n-3$ and $n$ - 6 Fatty acids are released from the cellular membrane by phospholipase enzymes. Long-chain PUFA are oxidised either non-enzymically by free radicals or by cyclo-oxygenase-1/2 (COX-1/2), 15-lipoxygenase (15-LOX) and 5-LOX enzymes to produce eicosanoid signalling metabolites. AA, arachidonic acid; AcCOX, aspirin-acetylated cyclo-oxygenase; 15-epi $L X A_{4}$, 15-epi lipoxin $A_{4}$; Rv, resolvin; $F_{2}$-IsoP, PG-like $F_{2}$ isoprostanes; TX, thromboxane; 15d-PGJ 2 , 15-deoxy- $\Delta^{12,14} \mathrm{PGJ}_{2}$; LA, linoleic acid; HPETE, hydroperoxyeicosatetraenoic acid; 15-oxoETE, 15-oxo-eicosatetraenoic acid; HETE, hydroxy-eicosatetraenoic acid; $M_{1}$, maresin; PD, protectin; HODE, hydroxy-octadecadienoic acid; 5-oxoETE, 5-oxo-eicosatetraenoic acid; LT, leukotriene. 
forms of COX-2 to produce E-series resolvins $(\mathrm{Rv})^{(63)}$, whereas 12/15-LOX converts DHA to the $\mathrm{D}$-series Rv, protectins (PD1) and the macrophage-specific maresin $\left(\mathrm{MaR}_{1}\right)$. During uncontrolled inflammation, a combination of exacerbated production of pro-inflammatory eicosanoids and diminished production of anti-inflammatory eicosanoids prevents full resolution and restoration of homeostasis ${ }^{(64)}$. Therefore, the balance between production of pro- and anti-inflammatory eicosanoids is one factor that determines the inflammatory phenotype of a cell/surrounding microenvironment ${ }^{(65)}$.

Eicosanoid abundance and timing of their production are crucial to successfully initiate and resolve inflammation. Eicosanoid biosynthesis is regulated at several levels and both Se and selenoproteins have been studied in the context of: (1) altering eicosanoid profiles as a function of manipulating dietary Se; (2) feedback loops from other eicosanoids; (3) chemically reducing lipid hydroperoxides; and (4) modifying expression and activity of COX/LOX enzymes (Table 2 and Fig. 5). However, research has just begun to uncover the underlying mechanisms of how Se can influence eicosanoid biosynthesis at each level of regulation.

\section{Selenium and eicosanoid profiles}

Previous studies have documented how dietary Se has an impact on the biosynthesis of eicosanoids in several different species. Following 2 years of supplementation, increased Se in the diet of human subjects $(100 \mu \mathrm{g} / \mathrm{d})$ was correlated with a decreased ratio of urinary 11-dehydro $\mathrm{TXB}_{2}: 2,3$ dinor 6-keto $\mathrm{PGF}_{1 \alpha}$. Increased ratios of $\mathrm{TXB}_{2}$ :6-keto $\mathrm{PGF}_{1 \alpha}$ are an indicative biomarker for thrombosis and atherosclerosis ${ }^{(66)}$ Previous research by Meydani ${ }^{(67)}$ and then Haberland et al. ${ }^{(68)}$ confirmed that adequate Se intake (300 $\mu \mathrm{g} \mathrm{Se} / \mathrm{kg}$ and $0.2 \mathrm{ppm}$, respectively) in rats can decrease the ratio of $\mathrm{TXB}_{2}: \mathrm{PGF}_{1 \alpha}$ following short-term ( 2 months) and long-term (eight generations) of dietary modulation, respectively. In dairy cattle with mastitis, Se-sufficient diets $(0.05 \mathrm{mg} \mathrm{Se} / \mathrm{kg})$ were associated with decreased pro-inflammatory $\mathrm{TXB}_{2}, \mathrm{PGE}_{2}$ and $\mathrm{LTB}_{4}$ eicosanoid production and secretion in milk compared with cows with deficient Se intake after 1 year of dietary interventions ${ }^{(69)}$. Taken together, these results indicate that dietary Se could potentially diminish pro-inflammatory eicosanoid biosynthesis during inflammatory diseases.

Se can also alter feedback loops involved with eicosanoid biosynthesis. One example was reported on the positive feedback loop involving the ability of 15 -deoxy- $\Delta^{12,14} \mathrm{PGJ}_{2}$ $\left(15 \mathrm{~d}-\mathrm{PGJ}_{2}\right)$ to perpetuate anti-inflammatory eicosanoid production by enhancing the expression of its upstream synthesis enzyme in macrophages. Compared with Se deficiency (6 $\mathrm{pmol} / \mathrm{ml}$ of Se from media FBS (fetal bovine serum) compared with cells supplemented with $250 \mathrm{~nm}$ ), culturing murine macrophages with Se to maximise GPx activity enhanced $15 \mathrm{~d}-\mathrm{PGJ}_{2}$ production; $15 \mathrm{~d}-\mathrm{PGJ}_{2}$ is a ligand for PPAR $\gamma$ that, once activated, enhanced H-PGDS (haematopoietic $\mathrm{PGD}_{2}$ synthase) expression. H-PGDS converts $\mathrm{PGH}_{2}$ to $\mathrm{PGD}_{2}$, which is an upstream metabolite of $15 \mathrm{~d}-\mathrm{PGJ}_{2}{ }^{(70)}$. Thus, depending on the level of regulation, Se could potentially dampen pro-inflammatory eicosanoid biosynthesis and enhance more anti-inflammatory eicosanoid production; however, more research is needed to determine the specific mechanisms involved at different levels of regulation of eicosanoid biosynthesis and which selenoproteins could have an effect.

\section{Antioxidant-dependent regulation of eicosanoid biosynthesis}

There is evidence that certain selenoproteins are at least partially responsible for the ability of Se to modify eicosanoid biosynthesis. A direct cause-and-effect relationship between GPx4 and LT production in cancer cells was previously explored by Imai et al. ${ }^{(71)}$. At the metabolite level, GPx4 overexpression was shown to reduce FAHP from the 5-LOX pathway (5-HPETE to 5-HETE), thus preventing the production of $\mathrm{LTB}_{4}$ and $\mathrm{C}_{4}$ in the leukaemia cell line ${ }^{(71)}$. The proposed mechanism was the antioxidant capabilities of GPx4 and the ability to reduce FAHP to hydroxyl derivatives. Others found that GPx4 reduced 15-HPETE to 15-HETE and preincubation of endothelial cells with GPx4 could prevent peroxide formation ${ }^{(72)}$. Both TrxR and Sepp1 also were shown

Table 2. The impact of selenium and selenoproteins on eicosanoid biosynthesis

\begin{tabular}{|c|c|c|}
\hline Se metabolite & Outcome resulting from sufficient levels of Se metabolite & Level of eicosanoid regulation \\
\hline $\mathrm{Se}$ & $\downarrow$ Phospholipase D activity & Substrate \\
\hline \multirow[t]{7}{*}{$\mathrm{Se}$} & $\uparrow \mathrm{H}-\mathrm{PDGS}$ & Enzyme expression \\
\hline & $\downarrow$ mPGES-1 & \\
\hline & $\uparrow \mathrm{PGIS}$ & \\
\hline & $\downarrow$ TXAS & \\
\hline & $\downarrow \mathrm{LTA}_{4} \mathrm{H}$ & \\
\hline & $\downarrow$ COX-2 & \\
\hline & $\downarrow 15$-LOX activity (haeme oxidation) & Enzyme activity \\
\hline GPx4 & $\downarrow$ Isoprostanes & Eicosanoid production \\
\hline Se & $\downarrow \mathrm{TXB}_{2}: 6-$ keto-PGF $\mathrm{F}_{1 \alpha}$ ratio & \\
\hline & $\downarrow \mathrm{TXB}_{2}$ & \\
\hline & $\downarrow \mathrm{LTB}_{4}$ & \\
\hline & $\downarrow \mathrm{PGE}_{2}, \mathrm{PGF}_{2 \alpha}$ & \\
\hline GPx1, 4 & Reduces HPETE to HETE & \\
\hline GPx1, 4 & Reduces HPODE to HODE & \\
\hline
\end{tabular}

$\downarrow$, Decrease; $\uparrow$, increase; H-PGDS, haematopoietic PGD 2 synthase; mPGES-1, microsomal PGE 2 synthase-1; PGIS, prostacyclin synthase; TXAS, thromboxane $A_{2}$ synthase; $\mathrm{LTA}_{4} \mathrm{H}$, leukotriene $\mathrm{A}_{4}$ hydrolase; COX-2, cyclo-oxygenase-2; 15-LOX, 15-lipoxygenase; GPx4, glutathione peroxidase-4; TXB ${ }_{2}$, thromboxane $B_{2}$; LTB $\mathrm{B}_{4}$, leukotriene $\mathrm{B}_{4}$; HPETE, hydroperoxyeicosatetraenoic acid; HETE, hydroxyeicosatetraenoic acid; HPODE, hydroperoxyoctadecadienoic acid; HODE, hydroxy-octadecadienoic acid. 

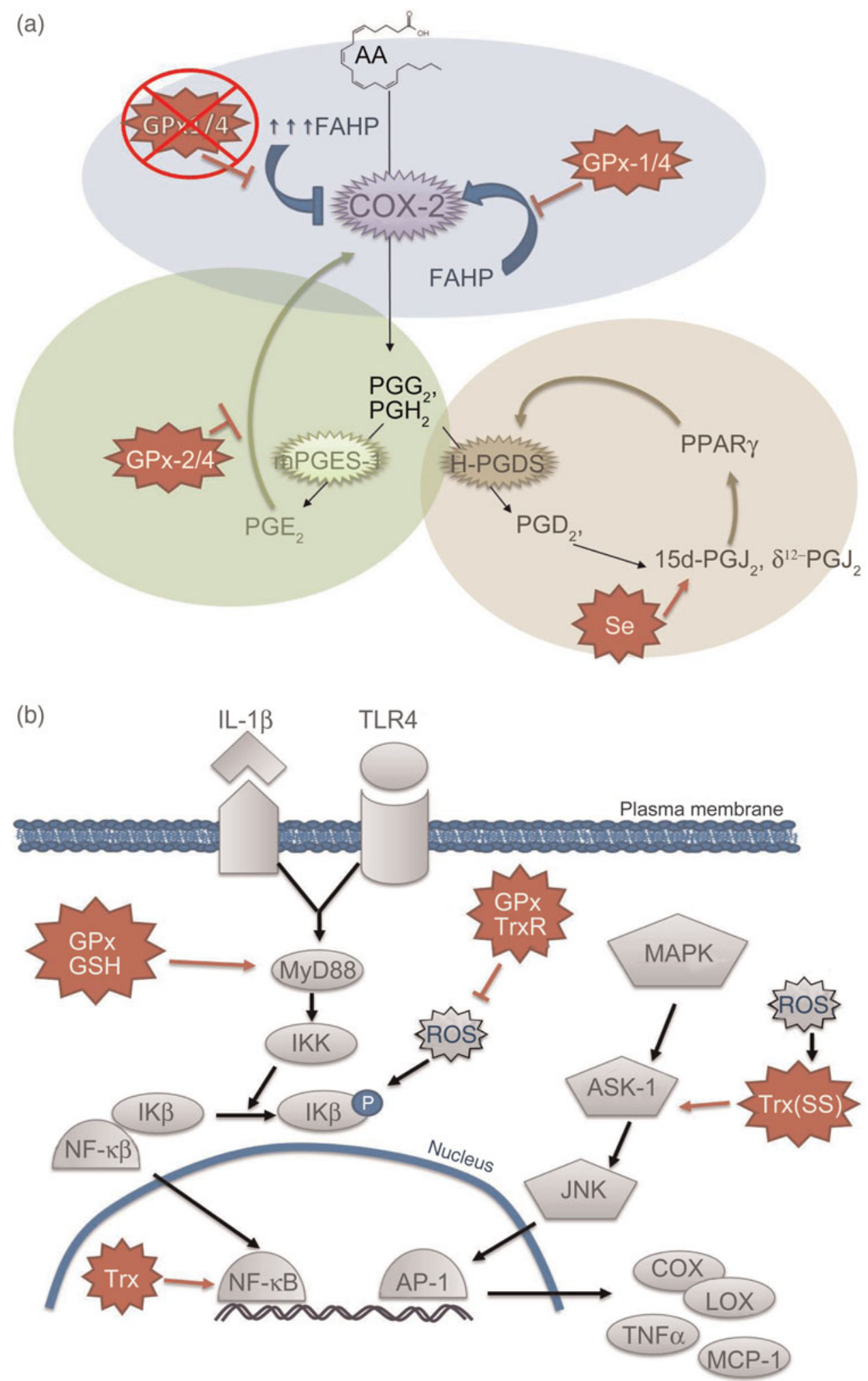

Fig. 5. Proposed interactions of selenium with eicosanoid biosynthesis pathways. (a) Selenium and selenoproteins interfere with eicosanoid feedback loops. While glutathione peroxidase (GPx)-1 and -4 can reduce fatty acid hydroperoxides (FAHP) to decrease cyclo-oxygenase-2 (COX-2) activity, a buildup of FAHP, when GPx activity is lacking, can also inhibit COX-2. GPx-2 and -4 diminish PGE $\mathrm{P}_{2}$-dependent expression of COX-2. Selenium enhances 15 -deoxy- ${ }^{12,14} \mathrm{PG} \mathrm{J}_{2}\left(15 \mathrm{~d}-\mathrm{PG} \mathrm{J}_{2}\right)$ production which is a ligand for PPAR $\gamma$. PPAR $\gamma$ signalling enhances haematopoietic $P G D_{2}$ synthase (H-PGDS), which synthesises $P G D_{2}$, an upstream metabolite of $15 d-P G J_{2}$. AA, arachidonic acid; mPGES-1, microsomal PGE 2 synthase-1. (b) Antioxidant selenoproteins can affect different signalling pathways leading to activation of NF- $\mathrm{kB}$ and activator protein-1 (AP-1) and expression of COX, lipoxygenase (LOX) and other inflammatory mediators such as TNF $\alpha$ and macrophage chemoattractant protein-1 (MCP-1). GPX can alter the redox state of the myeloid differentiation factor 88 (MyD88) adaptor protein, when MyD88 is denitrosylated by GPx with glutathione (GSH), signalling is enhanced. Reactive oxygen species (ROS)-mediated phosphorylation of inhibitor of $\mathrm{KB}$ (IKB) can be dampened when antioxidant selenoproteins are present to scavenge ROS. The mitogen-activated protein kinases (MAPK) can also be affected; ROS-mediated oxidation of thioredoxin (Trx) causes its dissociation from apoptosis signalregulating kinase 1 (ASK-1), enhancing signalling activity. In the nucleus, Trx can reduce oxidised cysteine residues on NF-kB, enhancing DNA binding and transcription. TLR4, toll-like receptor; TrxR, thioredoxin reductase; IKK, IKB kinase; Trx(SS), oxidised Trx; JNK, c-Jun N-terminal protein kinase. 
to have lipid hydryperoxidase activity for 15-HPETE, thus supporting the contention that these selenoproteins can function as antioxidant enzymes against highly reactive hydroperoxy intermediates formed during eicosanoid metabolism ${ }^{(35,37)}$. Collectively, these studies suggest that selenoproteins have an important role in protecting cells against oxidative damage caused by lipid hydroperoxides found in the eicosanoid network.

Individual selenoproteins also can modify eicosanoid biosynthesis through controlling the activity of COX/LOX enzymes. Walther et al. described how the Se-containing compound ebselen inhibited 15-LOX activity by altering the oxidation status of the active-site $\mathrm{Fe}$ molecule ${ }^{(73)}$. The activation of COX enzymes also requires oxidation of their active site haeme Fe to form a tyrosyl radical that is then capable of oxidising $\mathrm{AA}$ and other fatty acid substrates ${ }^{(74)}$. GPx1 can inhibit COX enzyme activity by chemically reducing hydroperoxides that could otherwise activate enzymic oxidation ${ }^{(75)}$. An abundance of eicosanoid metabolites and other radicals, however, can also inhibit the activity of eicosanoid enzymes through what is known as 'suicide inactivation', as described for $\operatorname{COX}^{(76)}$, PGI synthase ${ }^{(77)}$ and thromboxane $\mathrm{A}_{2}$ synthase (TXAS) ${ }^{(78)}$. A decrease in COX activity was described in human endothelial cells due to a buildup of peroxides during diminished GPx1 activity ${ }^{(79)}$. These findings suggest that cellular levels of FAHP are critical in COX enzyme activity; both an excess of FAHP or absence of these radicals can result in COX inhibition. This is interesting because GPx-mediated reduction of FAHP could have different effects on COX or LOX activity depending on the accumulation of FAHP. FAHP generated by the 15-LOX pathway were shown to be affected by another selenoprotein in vitro. Sepp1, a selenoprotein present in plasma, was shown to chemically reduce 15 -HPETE into 15 -HETE ${ }^{(37)}$. Additionally, Sepp1 decreased the production of free radicals following stimulation with 15-HPETE in vitro ${ }^{(37)}$. This study highlighted the antioxidant properties of the plasma selenoprotein, Sepp1, which could have significant implications in preventing oxidative stress associated with vascular inflammatory diseases, such as atherosclerosis.

\section{Redox regulation of eicosanoid biosynthesis}

Another way that Se can affect eicosanoid profiles is through the redox regulation of eicosanoid enzyme expression. Pre-treating chondrocytes with physiological levels of selenomethionine (Se-Met) $(0.5 \mu \mathrm{M})$ for $24 \mathrm{~h}$, for example, decreased IL-1 $\beta$-induced gene expression of COX-2 and consequent synthesis of $\mathrm{PGE}_{2}{ }^{(8)}$. Hwang et al. showed in mice that supplementation with $30 \mu \mathrm{g}$ selenate per g body weight for 2 weeks decreased tumour size and COX-2 expression in a model of colon cancer ${ }^{(80)}$. Addition of various supraphysiological doses of Se $(250-500 \mu \mathrm{M})$ to cultured HT-29 cells dampened extracellular signal-regulated kinase (ERK) signalling following stimulation with a tumour-promoting agent, 12-Otetradecanoylphorbol-13-acetate (TPA), and increased MAPK signalling; both of which decreased COX-2 expression ${ }^{(80)}$. In another model, prostate cancer cells (PC3) pre-treated with sodium selenite $(0 \cdot 5-5 \mu \mathrm{M})$ for 24 or $48 \mathrm{~h}$ had significantly decreased NF- $\mathrm{\kappa B}$ activity, which is another pathway known to control COX-2 expression ${ }^{(81)}$. As described earlier, the redox control of these signalling pathways can occur at several signalling intermediates. Collectively, these studies support the concept that Se can decrease COX-2 expression, at least in part, through the regulation of various redox-dependent signalling pathways. More research is needed, however, to characterise cause-and-effect relationships identifying where specific selenoproteins could be regulating COX-2 expression through other redox-regulated signalling pathways.

Selenium can affect eicosanoid biosynthesis in cancer models

Inflammatory pathways can play an important role in cancer development through regulation of cell proliferation and migration ${ }^{(82)}$. For example, eicosanoids can play an important role in tumorigenesis by regulating apoptosis and proliferation of cancer cells ${ }^{(83,84)}$ and Se may exert anti-cancerous properties through the manipulation of eicosanoid signalling. For example, Ghosh $e t a l .{ }^{(85)}$ reported that supplementation with various Se doses $(0-3 \mu \mathrm{M})$ for $72 \mathrm{~h}$ induced apoptosis of LNCaP human prostate cancer cells but not of normal PrEC prostate cells ${ }^{(85)}$. Additionally, they noted that stimulation of $\mathrm{LNCaP}$ with 5-LOX-derived eicosanoids, 5-HETE and 5-oxoETE (5-oxo-eicosatetraenoic acid), reversed Se's apoptotic effect and enhanced growth of cancerous cells, thus indicating that 5-LOX-derived eicosanoids may play a role in promoting cancerous cell growth in prostate cancer ${ }^{(85)}$. Other researchers explored the relationship between specific selenoproteins and eicosanoid regulation in models of colon cancer. In GPx2-silenced HT-29 colon cancer cells, an increase in COX-2 and microsomal $\mathrm{PGE}_{2}$ synthase-1 enzyme expression with a concomitant increase in $\mathrm{PGE}_{2}$ production was reported ${ }^{(5)}$. The authors proposed that GPx2 disrupted the positive feedback loop of $\mathrm{PGE}_{2}$-dependent expression of COX-2, representing a unique role specific for GPx2 in the colon cancer model ${ }^{(5)}$. This same feedback loop also was studied in the context of GPx4 and a fibrosarcoma cancer model. In L29 fibrosarcoma tumour cells, overexpression of GPx4 prevented tumour growth, decreased COX-2 expression and $\mathrm{PGE}_{2}$ production, and abrogated $\mathrm{PGE}_{2}$-dependent $\mathrm{COX}-2$ expression ${ }^{(86)}$. These studies provide examples in cancer models that the redox-regulating properties of certain selenoproteins could decrease pro-inflammatory eicosanoid production and reduce inflammatory-dependent tumour progression.

\section{Selenium's effect on eicosanoid biosynthesis in CVD models}

Atherosclerosis is another inflammatory-based disease that remains the leading cause of death in the developed world ${ }^{(1)}$. As such, interest is growing in understanding how Se may be beneficial in CVD models. Oxidative stress plays a significant role in the aetiology of cardiovascular lesion development by promoting the production of oxidised lipoproteins (oxLDL) and lipids such as the non-enzymically oxidised eicosanoids, PG-like $\mathrm{F}_{2}$ isoprostanes $\left(\mathrm{F}_{2}-\mathrm{IsoP}\right)^{(54)}$. These radicals, oxLDL in particular, are recognised and internalised by 
circulating monocytes which initiate foam cell development and macrophage infiltration into blood vessels ${ }^{(87)}$. The lipid hydroperoxide scavenging GPx4 was overexpressed in a mouse model of atherosclerosis $\left(\mathrm{ApoE}^{-/-}\right.$mice) which resulted in decreased overall atherosclerotic lesion development ${ }^{(33)}$. The mechanisms behind the protective effect of GPx4 in this study were thought to be enhanced through GPx4's antioxidant capabilities to decrease the accumulation of hydroperoxide radicals and diminish oxidative stress. In support of this theory, both $\mathrm{F}_{2}$-IsoP production and accumulation of intercellular and secreted hydroperoxides were significantly decreased in GPx4-overexpressing mouse aortic endothelial cells compared with atherosclerotic cells ${ }^{(33)}$. When mitochondrial GPx4 was overexpressed in a mouse ischaemia-reperfusion model, researchers documented significantly increased cardiac function and decreased lipid peroxidation $^{(34)}$. In another atherosclerosis model, $\mathrm{ApoE}^{-/-}$and GPx1 double knockout mice exhibited significantly increased atherosclerotic lesion development, suggesting that GPx1 may also play a role in disease progression ${ }^{(88)}$. Taken together, these data suggest that GPx could be a potential therapeutic target during heart disease due to their antioxidant properties and their capability to reduce lipid hydroperoxides and other radicals to less reactive lipid alcohols.

In addition to the antioxidant properties of selenoproteins, other possible mechanisms to explain Se's protective effects in an atherosclerosis disease model were examined. For example, Paniker et al. explored the impact of fatty acid substrate availability and downstream eicosanoid enzymic expression $^{(89)}$. In their study, sodium selenite $(8 \mu \mathrm{g} / 100 \mathrm{~g}$ body weight) supplementation for $30 \mathrm{~d}$ in isoproterenolinduced myocardial infarction in rats decreased LOX activity, leukotriene $\mathrm{A}_{4}$ hydrolase $\left(\mathrm{LTA}_{4} \mathrm{H}\right)$ expression, and $\mathrm{LTB}_{4}$ production in monocytes ${ }^{(89)}$. Se supplementation also decreased the amount of NEFA in the heart which can serve as substrates for LOX enzymic pathways. The expression of $\mathrm{LTA}_{4} \mathrm{H}$ was diminished and resulted in decreased $\mathrm{LTB}_{4}$ concentrations. By diminishing the expression of $\mathrm{LTA}_{4} \mathrm{H}$, the intermediate lipid metabolite $\mathrm{LTA}_{4}$ is prevented from being metabolised to the more pro-inflammatory eicosanoid $\mathrm{LTB}_{4}$, and preserved for the biosynthesis of resolving eicosanoids, such as $\mathrm{LXA}_{4}$. Although the mechanism behind the decrease in $\mathrm{LTA}_{4} \mathrm{H}$ in Se-treated animals was not explored, evidence suggests that specific enzymic pathways are potential target for Se-mediated treatment of uncontrolled inflammation. The current findings support the concept that antioxidant selenoproteins could play a role in controlling both non-enzymic and COX/LOX-mediated oxidation of lipid mediators during CVD. Further research is needed, however, to determine which antioxidant selenoproteins are most critical for regulating eicosanoid biosynthesis and lipid peroxide-mediated disease progression.

Selenium's impact on eicosanoids in specific cell-types: endothelial cells

Since many different cell types function in concert during inflammation, studies have focused on characterising the effects of Se on single-cell cultures to determine their role in inflammatory disease. Endothelial cells are an important component of the immune system. They are the barrier between the blood and tissue, regulate immune cell trafficking, and have been the focus of a number of studies on Se nutrition and eicosanoid biosynthesis. Confirmation that selenoprotein expression within endothelial cells is essential to survival was demonstrated when targeted knock out of selenoproteins in murine endothelial cells resulted in embryonic death due to haemorrhaging and erythrocyte immaturity ${ }^{(90)}$. The ability of Se to reduce lipid radical accumulation in endothelial cells was explored in early studies by $\mathrm{CaO}$ et al. ${ }^{(91)}$. Se-deficient bovine aortic endothelial cells cultured in the presence of only $0.01 \mathrm{ppm}$ Se were characterised by a significant decrease in GPx1 activity with concomitant increases in 15-HPETE and $\mathrm{TXB}_{2}$ compared with cells supplemented with $10 \mathrm{ng} / \mathrm{ml}$ sodium selenite ${ }^{(91)}$. The same group then explored the association between diminished Se status of endothelial cells and the ability of 15-HPETE to elicit signs of oxidative stress ${ }^{(36)}$, enhanced adhesion molecule expression ${ }^{(92)}$, higher rates of apoptosis ${ }^{(93)}$ and dampened expression of $\mathrm{PGI}_{2}{ }^{(94)}$. Collectively, these studies support the concept that the antioxidant ability of selenoproteins is necessary to mitigate the pro-inflammatory effects of 15-HPETE and reduce endothelial cell death as a consequence of oxidative stress. Evidence also supports a direct effect of TrxR in controlling oxidative stress and inflammation in vascular endothelial cells. Trigona et al. examined the role that TrxR activity may have on the differential regulation of the antioxidant enzyme haeme oxygenase-1 (HO-1) in 15-HPETE-challenged endothelial cells ${ }^{(36)}$. Silencing TrxR expression and activity prevented the compensatory increase in HO-1 when endothelial cells were stimulated with 15-HPETE. Additional experiments demonstrated that HO-1 induction was dependent on the TrxR redox activity since restoring intracellular levels of reduced Trx was sufficient to increase HO-1 expression when endothelial cells were cultured in Se-deficient media (less than $0.1 \mathrm{ppm} \mathrm{Se})^{(36)}$. This area requires more attention in future research, especially in the context of 15-LOX activity and redox-regulation of signalling that controls 15-LOXderived metabolite formation as there are some conflicting reports of the role of this pathway in disease progression. Whereas some researchers have found that enhancing 15-LOX enzyme activity leads to resolving eicosanoid production $^{(65)}$, others have found enhanced pro-inflammatory effects ${ }^{(95)}$. It will be necessary to identify how selenoproteins, such as TrxR1, affect the balance of pro- and antiinflammatory eicosanoids as a function of 15-LOX activity in endothelial cells to better understand their role in inflammatory responses.

Impact of selenium on eicosanoids in specific cell-types: leucocyte function

Lymphocytes are critical responders to inflammatory stimuli. They play a major role in inflammatory-based diseases including CVD by producing chemoattractants such as macrophage chemoattractant protein-1 (MCP-1) to enhance macrophage 
infiltration ${ }^{(96)}$. Lymphocytes are also important sources of eicosanoids and were studied in the context of Se nutrition. One group found significant decreases in eicosanoid production from lymphocytes obtained from rats fed a Se-deficient diet containing only $<0.05 \mathrm{mg} \mathrm{Se} / \mathrm{kg}^{(97)}$. The underlying mechanism behind the decrease in eicosanoid biosynthesis was proposed to be that Se-deficient lymphocytes had significantly diminished phospholipase D activation which is responsible for liberating fatty acid substrates from cellular membranes. Future studies should focus on determining how antioxidant selenoproteins can specifically affect the expression and activity of phospholipases, potentially through redox regulation, and how this may affect the eicosanoids produced during inflammation.

Macrophages are especially crucial in pathogen recognition and orchestration of inflammation. Since macrophages synthesise copious amount of ROS to aid in pathogen destruction, they rely on selenoprotein antioxidants to reduce excess radicals that have the potential to cause self-damage ${ }^{(98)}$. Macrophages were acknowledged as a key cell type in the early development of atherosclerosis because they are responsible for recognising and ingesting oxidised lipoproteins (oxLDL) $^{(87)}$. Macrophages were the focus of several reports characterising eicosanoid regulation as a function of Se status. Prabhu et al. were interested in exploring the relationship between Se nutrition and the pro-inflammatory signalling pathway, $N F-\kappa B^{(99)}$. These investigators described an association between enhanced $\mathrm{NF}-\kappa \mathrm{B}$ activity in macrophages cultured in media containing only $6 \mathrm{pmol} / \mathrm{ml}$ of Se when compared with cells supplemented with $2 \mathrm{nmol} / \mathrm{ml}$ of sodium selenite $^{(99)}$. Additional studies proved that a significant increase in COX-2 enzyme expression during Se deficiency was mediated through increased $\mathrm{NF}-\kappa \mathrm{B}$ activity ${ }^{(100)}$. In contrast, Se supplementation $(20-50 \mu \mathrm{M})$ was able to decreased $\mathrm{NF}-\kappa \mathrm{B}$ activation and COX-2 expression through the toll-like receptor (TLR4) pathway ${ }^{(101)}$. In microglial cells (macrophages specific to the central nervous system and brain), pre-treating cells with Se-containing compounds $(0-10 \mu \mathrm{M})$ decreased lipopolysaccharide (LPS)-induced $\mathrm{NF}-\mathrm{\kappa B}$ activation, COX-2 expression and $\mathrm{PGE}_{2}$ production ${ }^{(102)}$. Collectively, these studies suggest that $\mathrm{Se}$, through the activity of antioxidant selenoproteins, could mediate eicosanoid biosynthesis by control-

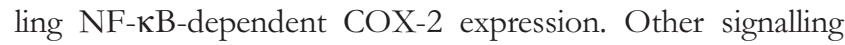
pathways also may be involved in regulating COX-2 expression and the subsequent metabolism of lipids through this pathway. For example, LPS-stimulated macrophages cultured in Se-supplemented media $(0 \cdot 1 \mu \mathrm{M}$-sodium selenite) led to a significant decrease in LPS-induced expression of COX-2 and TNF- $\alpha$ by inhibition of the MAPK signalling pathway ${ }^{(45)}$. Additional experiments demonstrated that mice maintained on a Se-deficient diet had significant increases in LPS-mediated infiltration of lung macrophages when compared with animals maintained on a Se-adequate diet ${ }^{(45)}$. One way that Se status was suggested to alter macrophage inflammatory properties was through changes in the profile of COX-derived eicosanoids. Macrophages cultured in Se-supplemented media $(0 \cdot 1 \mu \mathrm{M}$-sodium selenite) demonstrated a time-dependent increase in the production of
$15 \mathrm{~d}-\mathrm{PGJ}_{2}$ which is an endogenous inhibitor of $\mathrm{NF}-\kappa \mathrm{B}$ activation $^{(44)}$. Recently, reports showed that downstream eicosanoid synthase enzymes also are affected by selenoproteins $^{(70)}$. Se supplementation $(0 \cdot 1 \mu \mathrm{M})$ enhanced macrophage expression of H-PGDS and the subsequent increase in $\Delta^{12}-\mathrm{PGJ}_{2}$ and $15 \mathrm{~d}-\mathrm{PGJ}_{2}$ production. These effects where mediated by selenoproteins as confirmed by silencing selenoprotein expression through selenophosphate synthatase 2 in macrophages. On the other hand, microsomal $\mathrm{PGE}_{2}$ synthase and thromboxane $A_{2}$ synthase (TXAS) were decreased during Se supplementation ${ }^{(70)}$. Together, these studies have begun to demonstrate the association between antioxidant selenoproteins and different levels of eicosanoid regulation in macrophages through several different mechanisms including modification of signalling (i.e. NF- $\mathrm{B}, \mathrm{MAPK}$ ) to affect COX/LOX expression, manipulating downstream eicosanoid synthase expression, altering the production of specific eicosanoids, and disrupting eicosanoid feedback loops. However, more research is warranted to determine which specific selenoproteins are responsible for these effects in order to gain a better understanding of where in the eicosanoid cascade that Se nutritional intervention may be possible.

\section{Conclusions}

Uncontrolled inflammation, governed in part by eicosanoids, is recognised to play a prominent role in the major lifethreatening diseases of the developed world. Although the beneficial anti-inflammatory properties of Se have been appreciated for many years, the underlying mechanisms of action are not fully understood. There is ample evidence to suggest that optimal Se nutrition can combat uncontrolled inflammation, at least in part, because of the antioxidant and redox-regulating capabilities of selenoproteins. Considerably less is known, however, about the specific selenoproteins that are responsible for these regulatory mechanisms and dynamic changes in their activity that occur during inflammatory processes. More recently, there is a growing body of evidence that further highlights the importance of selenoprotein-dependent regulation of eicosanoid biosynthesis in controlling inflammatory responses. Antioxidant selenoproteins can reduce FAHP and lipid radicals directly, affecting eicosanoid stability as well as phospholipase and COX/LOX activity. Certain selenoproteins also can regulate cellular redox tone which has implications on cell signalling through $\mathrm{NF}-\kappa \mathrm{B}$ and MAPK pathways, all of which can control expression of COX/LOX enzymes. A major gap in the existing literature, however, is knowledge of how specific selenoproteins can modify eicosanoid networks in such a way as to switch from a pro-inflammatory to resolution state and thereby mitigate uncontrolled inflammatory responses that lead to disease pathogenesis. With the advent of new lipidomic analytical techniques ${ }^{(103)}$, it should now be possible to conduct more detailed investigations of how specific selenoproteins, acting individually or in concert with others, can alter the global expression of eicosanoids relevant to specific disease models. Genomic-based approaches also will be necessary to evaluate the differential expression of selenoproteins in various 
tissues and how selenoprotein activity can affect eicosanoid biosynthesis in different cells involved in the inflammatory response. Some of the equivocal findings from existing clinical studies involving Se nutritional status can be attributed to the lack of information that links dietary intakes of Se-rich foods with tissue levels of selenoproteins that are needed to modify specific inflammatory-regulating biological responses. More precise details of how selenoproteins can modify eicosanoid metabolism may not only identify relevant therapeutic targets, but also provide accurate biomarkers for assessing optimal Se intake. A better understanding of the mechanisms involved in Se-mediated regulation of host inflammatory responses will lead to more efficient and consistent nutritional intervention strategies than what has been achieved to date.

\section{Acknowledgements}

The present study was supported, in part, by the Agriculture and Food Research Initiative Competitive Grants Program (no. 2011-67015-30179 and no. 2012-67011-19944) from the US Department of Agriculture National Institute for Food and Agriculture and by an endowment from the Matilda R. Wilson Fund (Detroit, MI, USA).

Authors contributed as follows: S. A. M. prepared and wrote the manuscript, B. A. C. and L. M. S. contributed to the writing and editing of the manuscript. All authors proofread and approved the final draft.

There are no conflicts of interest to declare.

\section{References}

1. Lloyd-Jones D, Adams R, Carnethon M, et al. (2009) Heart disease and stroke statistics - 2009 update. Circulation 119, e21-e181.

2. Boosalis MG (2008) The role of selenium in chronic disease. Nutr Clin Pract 23, 152-160.

3. Sordillo LM, Contreras GA \& Aitken SL (2009) Metabolic factors affecting the inflammatory response of periparturient dairy cows. Anim Health Res Rev 10, 53-63.

4. Van der Linden MW, Van der Bij S, Welsing P, et al. (2009) The balance between severe cardiovascular and gastrointestinal events among users of selective and non-selective non-steroidal antiinflammatory drugs. Ann Rheum Dis 68, 668-673.

5. Banning A, Florian S, Deubel S, et al. (2008) GPx2 counteracts PGE2 production by dampening COX-2 and mPGES-1 expression in human colon cancer cells. Antioxid Redox Signal 10, 1491-1500.

6. Flores-Mateo G, Navas-Acien A, Pastor-Barriuso R, et al. (2006) Selenium and coronary heart disease: a meta-analysis. Am J Clin Nutr 84, 762-773.

7. Aitken SL, Karcher EL, Rezamand P, et al. (2009) Evaluation of antioxidant and proinflammatory gene expression in bovine mammary tissue during the periparturient period. J Dairy Sci 92, 589-598.

8. Cheng AWM, Stabler TV, Bolognesi M, et al. (2011) Selenomethionine inhibits IL-1 $\beta$ inducible nitric oxide synthase (iNOS) and cyclooxygenase 2 (COX2) expression in primary human chondrocytes. Osteoarthritis Cartilage 19, 118-125.

9. Moxon AL \& Rhian M (1943) Selenium poisoning. Physiol Rev 23, 305-337.

10. Muth O, Oldfield J, Remmert L, et al. (1958) Effects of selenium and vitamin E on white muscle disease. Science 128, 1090-1091.

11. Chen X, Yang G, Chen J, et al. (1980) Studies on the relations of selenium and Keshan disease. Biol Trace Elem Res 2, 91-107.
12. Monsen ER (2000) Dietary reference intakes for the antioxidant nutrients: vitamin $\mathrm{C}$, vitamin $\mathrm{E}$, selenium, and carotenoids. J Am Diet Assoc 100, 637-640.

13. Abdo KM (1994) NTP Technical Report on Toxicity Studies of Sodium Selenate and Sodium Selenite (CAS Nos. 13410-01-0 and 10102-18-8) Administered in Drinking Water to F344/N Rats and B6C3F1 Mice. Research Triangle Park: NTP Central Data Management.

14. Huang T-S, Shyu Y-C, Chen H-Y, et al. (2013) Effect of parenteral selenium supplementation in critically ill patients: a systematic review and meta-analysis. PLOS ONE 8, e54431.

15. Ghaemi S, Forouhari S, Dabbaghmanesh M, et al. (2013) A prospective study of selenium concentration and risk of preeclampsia in pregnant Iranian women: a nested case-control study. Biol Trace Elem Res 152, 174-179.

16. Tirosh O, Levy E \& Reifen R (2007) High selenium diet protects against TNBS-induced acute inflammation, mitochondrial dysfunction, and secondary necrosis in rat colon. Nutrition 23, 878-886.

17. Lippman SM, Klein EA, Goodman PJ, et al. (2009) Effect of selenium and vitamin $E$ on risk of prostate cancer and other cancers: the Selenium and Vitamin E Cancer Prevention Trial (SELECT). $J A M A$ 301, 39-51.

18. Hamilton JW \& Tappel AL (1963) Lipid antioxidant activity in tissues and proteins of selenium-fed animals. J Nutr 79, 493-502.

19. Sordillo LM \& Aitken SL (2009) Impact of oxidative stress on the health and immune function of dairy cattle. Vet Immunol Immunopathol 128, 104-109.

20. Sies H (1986) Biochemistry of oxidative stress. Angew Chemie Int Edit 25, 1058-1071.

21. Kernstock RM \& Girotti AW (2008) New strategies for the isolation and activity determination of naturally occurring type- 4 glutathione peroxidase. Protein Express Purif 62, 216-222.

22. Thomas JP, Maiorino M, Ursini F, et al. (1990) Protective action of phospholipid hydroperoxide glutathione peroxidase against membrane-damaging lipid peroxidation. In situ reduction of phospholipid and cholesterol hydroperoxides. J Biol Chem 265, 454-461.

23. Pushpa-Rekha TR, Burdsall AL, Oleksa LM, et al. (1995) Rat phospholipid-hydroperoxide glutathione peroxidase: cDNA cloning and identification of multiple transcription and translation start sites. J Biol Chem 270, 26993-26999.

24. Liang H, Remmen HV, Frohlich V, et al. (2007) Gpx4 protects mitochondrial ATP generation against oxidative damage. Biochem Biophys Res Commun 356, 893-898.

25. Fairweather-Tait SJ, Bao Y, Broadley MR, et al. (2011) Selenium in human health and disease. Antioxid Redox Signal 14, 1337-1383.

26. Jeong D-W, Kim TS, Chung YW, et al. (2002) Selenoprotein W is a glutathione-dependent antioxidant in vivo. FEBS Lett 517, 225-228.

27. Praticò D, Tangirala RK, Rader DJ, et al. (1998) Vitamin E suppresses isoprostane generation in vivo and reduces atherosclerosis in apoE-deficient mice. Nat Med 4, 1189-1192.

28. Monnier L, Mas E, Ginet C, et al. (2006) Activation of oxidative stress by acute glucose fluctuations compared with sustained chronic hyperglycemia in patients with type 2 diabetes. JAMA 295, 1681-1687.

29. Ranjan R, Swarup D, Naresh R, et al. (2005) Enhanced erythrocytic lipid peroxides and reduced plasma ascorbic acid, and alteration in blood trace elements level in dairy cows with mastitis. Vet Res Comm 29, 27-34.

30. Bellinger FP, Raman AV, Reeves MA, et al. (2009) Regulation and function of selenoproteins in human disease. Biochem J 422, 11-22.

31. Lu J \& Holmgren A (2009) Selenoproteins. J Biol Chem 284, 723-727.

32. Sordillo LM (2013) Selenium-dependent regulation of oxidative stress and immunity in periparturient dairy cattle. Vet Med $\operatorname{Int2013,} 154045$.

33. Guo Z, Ran Q, Roberts LJ II, et al. (2008) Suppression of atherogenesis by overexpression of glutathione peroxidase- 4 in apolipoprotein E-deficient mice. Free Radic Biol Med 44, 343-352.

34. Dabkowski ER, Williamson CL \& Hollander JM (2008) Mitochondria-specific transgenic overexpression of phospholipid hydroperoxide glutathione peroxidase (GPx4) attenuates 
ischemia/reperfusion-associated cardiac dysfunction. Free Radic Biol Med 45, 855-865.

35. Björnstedt M, Hamberg M, Kumar S, et al. (1995) Human thioredoxin reductase directly reduces lipid hydroperoxides by NADPH and selenocystine strongly stimulates the reaction via catalytically generated selenols. J Biol Chem 270, 11761-11764.

36. Trigona WL, Mullarky IK, Cao Y, et al. (2006) Thioredoxin reductase regulates the induction of haem oxygenase-1 expression in aortic endothelial cells. Biochem J 394, 207-216.

37. Rock C \& Moos PJ (2010) Selenoprotein P protects cells from lipid hydroperoxides generated by 15-LOX-1. Prostaglandins Leukot Essent Fatty Acids 83, 203-210.

38. George J, Afek A, Shaish A, et al. (2001) 12/15-Lipoxygenase gene disruption attenuates atherogenesis in LDL receptor-deficient mice. Circulation 104, 1646-1650.

39. Schafer FQ \& Buettner GR (2001) Redox environment of the cell as viewed through the redox state of the glutathione disulfide/glutathione couple. Free Radic Biol Med 30, 1191-1212.

40. Into T, Inomata M, Nakashima M, et al. (2008) Regulation of MyD88-dependent signaling events by $\mathrm{S}$ nitrosylation retards tolllike receptor signal transduction and initiation of acute-phase immune responses. Mol Cell Biol 28, 1338-1347.

41. Al-Gayyar MM, Abdelsaid MA, Matragoon S, et al. (2011) Thioredoxin interacting protein is a novel mediator of retinal inflammation and neurotoxicity. Br J Pharmacol 164, 170-180.

42. Kataoka K, Tokutomi Y, Yamamoto E, et al. (2011) Apoptosis signal-regulating kinase 1 deficiency eliminates cardiovascular injuries induced by high-salt diet. J Hypertens $29,76-84$.

43. Saitoh M, Nishitoh H, Fujii M, et al. (1998) Mammalian thioredoxin is a direct inhibitor of apoptosis signal-regulating kinase (ASK) 1. EMBO J 17, 2596-2606.

44. Vunta H, Davis F, Palempalli UD, et al. (2007) The antiinflammatory effects of selenium are mediated through 15-deoxy-12,14-prostaglandin J2 in macrophages. J Biol Chem 282, 17964-17973.

45. Vunta H, Belda BJ, Arner RJ, et al. (2008) Selenium attenuates pro-inflammatory gene expression in macrophages. Mol Nutr Food Res 52, 1316-1323.

46. Allard JP, Aghdassi E, Chau J, et al. (1998) Oxidative stress and plasma antioxidant micronutrients in humans with HIV infection. Am J Clin Nutr 67, 143-147.

47. Gladyshev VN, Stadtman TC, Hatfield DL, et al. (1999) Levels of major selenoproteins in T cells decrease during HIV infection and low molecular mass selenium compounds increase. Proc Natl Acad Sci U S A 96, 835-839.

48. Jamaluddin M, Wang S, Boldogh I, et al. (2007) TNF- $\alpha$-induced NF- $\mathrm{BB} /$ RelA Ser276 phosphorylation and enhanceosome formation is mediated by an ROS-dependent PKAc pathway. Cell Signal 19, 1419-1433.

49. Meyer M, Schreck R \& Baeuerle PA (1993) $\mathrm{H}_{2} \mathrm{O}_{2}$ and antioxidants have opposite effects on activation of NF-kB and AP-1 in intact cells: AP-1 as secondary antioxidant-responsive factor. EMBO J 12, 2005-2015.

50. Matthews JR, Wakasugi N, Virelizier JL, et al. (1992) Thioredoxin regulates the DNA binding activity of NF- $\mathrm{KB}$ by reduction of a disulphide bond involving cysteine 62. Nucleic Acids Res 20, 3821-3830.

51. Hirota K, Murata M, Sachi Y, et al. (1999) Distinct roles of thioredoxin in the cytoplasm and in the nucleus: a two-step mechanism of redox regulation of transcription factor NF-кB. J Biol Chem 274, 27891-27897.

52. Schmitz G \& Ecker J (2008) The opposing effects of $n-3$ and $n-6$ fatty acids. Prog Lipid Res 47, 147-155.

53. Roberts LJ II \& Morrow JD (2000) Measurement of F2-isoprostanes as an index of oxidative stress in vivo. Free Radic Biol Med 28, 505-513.

54. Lakshmi S, Padmaja G, Kuppusamy P, et al. (2009) Oxidative stress in cardiovascular disease. Indian J Biochem Biophys 46, $421-440$.
55. Spiteller P \& Spiteller G (1997) 9-Hydroxy-10,12-octadecadienoic acid (9-HODE) and 13-hydroxy-9,11-octadecadienoic acid (13-HODE): excellent markers for lipid peroxidation. Chem Phys Lipids 89, 131-139.

56. Xie WL, Chipman JG, Robertson DL, et al. (1991) Expression of a mitogen-responsive gene encoding prostaglandin synthase is regulated by mRNA splicing. Proc Natl Acad Sci U S A 88, 2692-2696.

57. Kurumbail RG, Kiefer JR \& Marnett LJ (2001) Cyclooxygenase enzymes: catalysis and inhibition. Curr Opin Struct Biol 11, 752-760.

58. Dubois RN, Abramson SB, Crofford L, et al. (1998) Cyclooxygenase in biology and disease. FASEB J 12, 1063-1073.

59. Kuhn H \& Thiele BJ (1999) The diversity of the lipoxygenase family: many sequence data but little information on biological significance. FEBS Lett 449, 7-11.

60. Chiang N, Arita M \& Serhan CN (2005) Anti-inflammatory circuitry: lipoxin, aspirin-triggered lipoxins and their receptor ALX. Prostaglandins Leukot Essent Fatty Acids 73, 163-177.

61. Kuhn H \& O'Donnell VB (2006) Inflammation and immune regulation by 12/15-lipoxygenases. Prog Lipid Res 45, 334-356.

62. Yuan ZX, Rapoport SI, Soldin SJ, et al. (2013) Identification and profiling of targeted oxidized linoleic acid metabolites in rat plasma by quadrupole time-of-flight mass spectrometry. Biomed Chromatogr 27, 422-432.

63. Oh SF, Dona M, Fredman G, et al. (2012) Resolvin E2 formation and impact in inflammation resolution. J Immunol 188, 4527-4534.

64. Merched AJ, Ko K, Gotlinger KH, et al. (2008) Atherosclerosis: evidence for impairment of resolution of vascular inflammation governed by specific lipid mediators. FASEB J 22, 3595-3606.

65. Serhan CN \& Savill J (2005) Resolution of inflammation: the beginning programs the end. Nat Immunol 6, 1191-1197.

66. Arnaud J, Bost M, Vitoux D, et al. (2007) Effect of low dose antioxidant vitamin and trace element supplementation on the urinary concentrations of thromboxane and prostacyclin metabolites. J Am Coll Nutr 26, 405-411.

67. Meydani M (1992) Modulation of the platelet thromboxane A2 and aortic prostacyclin synthesis by dietary selenium and vitamin E. Biol Trace Elem Res 33, 79-86.

68. Haberland A, Neubert K, Kruse I, et al. (2001) Consequences of long-term selenium-deficient diet on the prostacyclin and thromboxane release from rat aorta. Biol Trace Elem Res 81, 71-78.

69. Maddox JF, Reddy CC, Eberhart RJ, et al. (1991) Dietary selenium effects on milk eicosanoid concentration in dairy cows during coliform mastitis. Prostaglandins 42, 369-378.

70. Gandhi UH, Kaushal N, Ravindra KC, et al. (2011) Selenoprotein-dependent upregulation of hematopoietic prostaglandin D2 synthase in macrophages is mediated through the activation of peroxisome proliferator-activated receptor (PPAR) $\gamma$. J Biol Chem 286, 27471-27482.

71. Imai H, Narashima K, Arai M, et al. (1998) Suppression of leukotriene formation in RBL-2H3 cells that overexpressed phospholipid hydroperoxide glutathione peroxidase. J Biol Chem 273, 1990-1997.

72. Schnurr K, Belkner J, Ursini F, et al. (1996) The selenoenzyme phospholipid hydroperoxide glutathione peroxidase controls the activity of the 15-lipoxygenase with complex substrates and preserves the specificity of the oxygenation products. J Biol Chem 271, 4653-4658.

73. Walther M, Holzhutter H-G, Kuban RJ, et al. (1999) The inhibition of mammalian 15-lipoxygenases by the anti-inflammatory drug ebselen: dual-type mechanism involving covalent linkage and alteration of the iron ligand sphere. Mol Pharmacol 56, 196-203.

74. Marnett LJ, Rowlinson SW, Goodwin DC, et al. (1999) Arachidonic acid oxygenation by COX-1 and COX-2. J Biol Chem 274, 22903-22906.

75. Cook H \& Lands WEM (1976) Mechanism for suppression of cellular biosynthesis of prostaglandins. Nature 260, 630-632.

76. Smith WL \& Lands WEM (1972) Oxygenation of polyunsaturated fatty acids during prostaglandin biosynthesis by sheep vesicular glands. Biochemistry 11, 3276-3285. 
77. Wade ML, Voelkel NF \& Fitzpatrick FA (1995) "Suicide" inactivation of prostaglandin I2 synthase: characterization of mechanism-based inactivation with isolated enzyme and endothelial cells. Arch Biochem Biophys 321, 453-458.

78. Jones DA \& Fitzpatrick FA (1990) "Suicide" inactivation of thromboxane A2 synthase. Characteristics of mechanism-based inactivation with isolated enzyme and intact platelets. J Biol Chem 265, 20166-20171.

79. Hampel G, Watanabe K, Weksler BB, et al. (1989) Selenium deficiency inhibits prostacyclin release and enhances production of platelet activating factor by human endothelial cells. Biochim Biophys Acta 1006, 151-158.

80. Hwang J-T, Kim YM, Surh Y-J, et al. (2006) Selenium regulates cyclooxygenase-2 and extracellular signal-regulated kinase signaling pathways by activating AMP-activated protein kinase in colon cancer cells. Cancer Res 66, 10057-10063.

81. Pei Z, Li H, Guo Y, et al. (2010) Sodium selenite inhibits the expression of VEGF, TGF $\beta 1$ and IL- 6 induced by LPS in human PC3 cells via TLR4-NF-KB signaling blockage. Int Immunopharmacol 10, 50-56.

82. Coussens LM, Zitvogel L \& Palucka AK (2013) Neutralizing tumor-promoting chronic inflammation: a magic bullet? Science 339, 286-291.

83. Sheng H, Shao J, Morrow JD, et al. (1998) Modulation of apoptosis and Bcl-2 expression by prostaglandin E2 in human colon cancer cells. Cancer Res 58, 362-366.

84. Avis I, Hong SH, Martínez A, et al. (2001) Five-lipoxygenase inhibitors can mediate apoptosis in human breast cancer cell lines through complex eicosanoid interactions. FASEB J 15, 2007-2009.

85. Ghosh J (2004) Rapid induction of apoptosis in prostate cancer cells by selenium: reversal by metabolites of arachidonate 5-lipoxygenase. Biochem Biophys Res Commun 315, 624-635.

86. Heirman I, Ginneberge D, Brigelius-Flohé R, et al. (2006) Blocking tumor cell eicosanoid synthesis by GPx4 impedes tumor growth and malignancy. Free Radic Biol Med 40, 285-294.

87. Quinn MT, Parthasarathy S, Fong LG, et al. (1987) Oxidatively modified low density lipoproteins: a potential role in recruitment and retention of monocyte/macrophages during atherogenesis. Proc Natl Acad Sci U S A 84, 2995-2998.

88. Lewis P, Stefanovic N, Pete J, et al. (2007) Lack of the antioxidant enzyme glutathione peroxidase-1 accelerates atherosclerosis in diabetic apolipoprotein E-deficient mice. Circulation 115, 2178-2187.

89. Panicker S, Swathy S \& John F (2012) Impact of selenium on the leukotriene B4 synthesis pathway during isoproterenolinduced myocardial infarction in experimental rats. Inflammation 35, 74-80.

90. Shrimali RK, Weaver JA, Miller GF, et al. (2007) Selenoprotein expression is essential in endothelial cell development and cardiac muscle function. Neuromuscul Disord 17, 135-142.
91. Cao Y-Z, Reddy CC \& Sordillo LM (2000) Altered eicosanoid biosynthesis in selenium-deficient endothelial cells. Free Radic Biol Med 28, 381-389.

92. Sordillo LM, Streicher KL, Mullarky IK, et al. (2008) Selenium inhibits 15-hydroperoxyoctadecadienoic acid-induced intracellular adhesion molecule expression in aortic endothelial cells. Free Radic Biol Med 44, 34-43.

93. Sordillo LM, Weaver JA, Cao Y-Z, et al. (2005) Enhanced 15-HPETE production during oxidant stress induces apoptosis of endothelial cells. Prostaglandins Other Lipid Mediat 76, 19-34.

94. Weaver JA, Maddox JF, Cao YZ, et al. (2001) Increased 15-HPETE production decreases prostacyclin synthase activity during oxidant stress in aortic endothelial cells. Free Radic Biol Med 30, 299-308.

95. Rydberg EK, Krettek A, Ullström C, et al. (2004) Hypoxia increases LDL oxidation and expression of 15-lipoxygenase-2 in human macrophages. Arterioscler Thromb Vasc Biol 24, 2040-2045.

96. Takahashi K, Takeya M \& Sakashita N (2002) Multifunctional roles of macrophages in the development and progression of atherosclerosis in humans and experimental animals. Med Electron Microsc 35, 179-203.

97. Cao Y-Z, Weaver JA, Chana Reddy C, et al. (2002) Selenium deficiency alters the formation of eicosanoids and signal transduction in rat lymphocytes. Prostaglandins Other Lipid Mediat 70, 131-143.

98. Carlson B, Yoo M-H, Sano Y, et al. (2009) Selenoproteins regulate macrophage invasiveness and extracellular matrix-related gene expression. BMC Immunol 10, 57.

99. Prabhu KS, Zamamiri-Davis F, Stewart JB, et al. (2002) Selenium deficiency increases the expression of inducible nitric oxide synthase in RAW 264.7 macrophages: role of nuclear factor- $\kappa \mathrm{B}$ in up-regulation. Biochem J 366, 203-209.

100. Zamamiri-Davis F, Lu Y, Thompson JT, et al. (2002) Nuclear factor- $\kappa \mathrm{B}$ mediates over-expression of cyclooxygenase-2 during activation of RAW 264.7 macrophages in selenium deficiency. Free Radic Biol Med 32, 890-897.

101. Youn H-S, Lim HJ, Choi YJ, et al. (2008) Selenium suppresses the activation of transcription factor NF- $\mathrm{\kappa B}$ and IRF3 induced by TLR3 or TLR4 agonists. Int Immunopharmacol 8, 495-501.

102. Nam KN, Koketsu M \& Lee EH (2008) 5-Chloroacetyl-2-amino1,3-selenazoles attenuate microglial inflammatory responses through NF-кB inhibition. Eur J Pharmacol 589, 53-57.

103. Serhan CN \& Chiang N (2008) Endogenous pro-resolving and anti-inflammatory lipid mediators: a new pharmacologic genus. Br J Pharmacol 153, Suppl. 1, S200-S215.

104. Heras IL, Palomo M \& Madrid Y (2011) Selenoproteins: the key factor in selenium essentiality. State of the art analytical techniques for selenoprotein studies. Anal Bioanal Chem 400, 1717-1727.

105. Kryukov GV, Castellano S, Novoselov SV, et al. (2003) Characterization of mammalian selenoproteomes. Science 300, 1439-1443. 